\title{
Declining risk of ozone impacts on vegetation in Europe 1990-2050 due to reduced precursor emissions in a changed climate
}

\author{
J. Klingberg, M. Engardt, P. E. Karlsson, J. Langner and H. Pleijel
}

\section{Supplementary material}
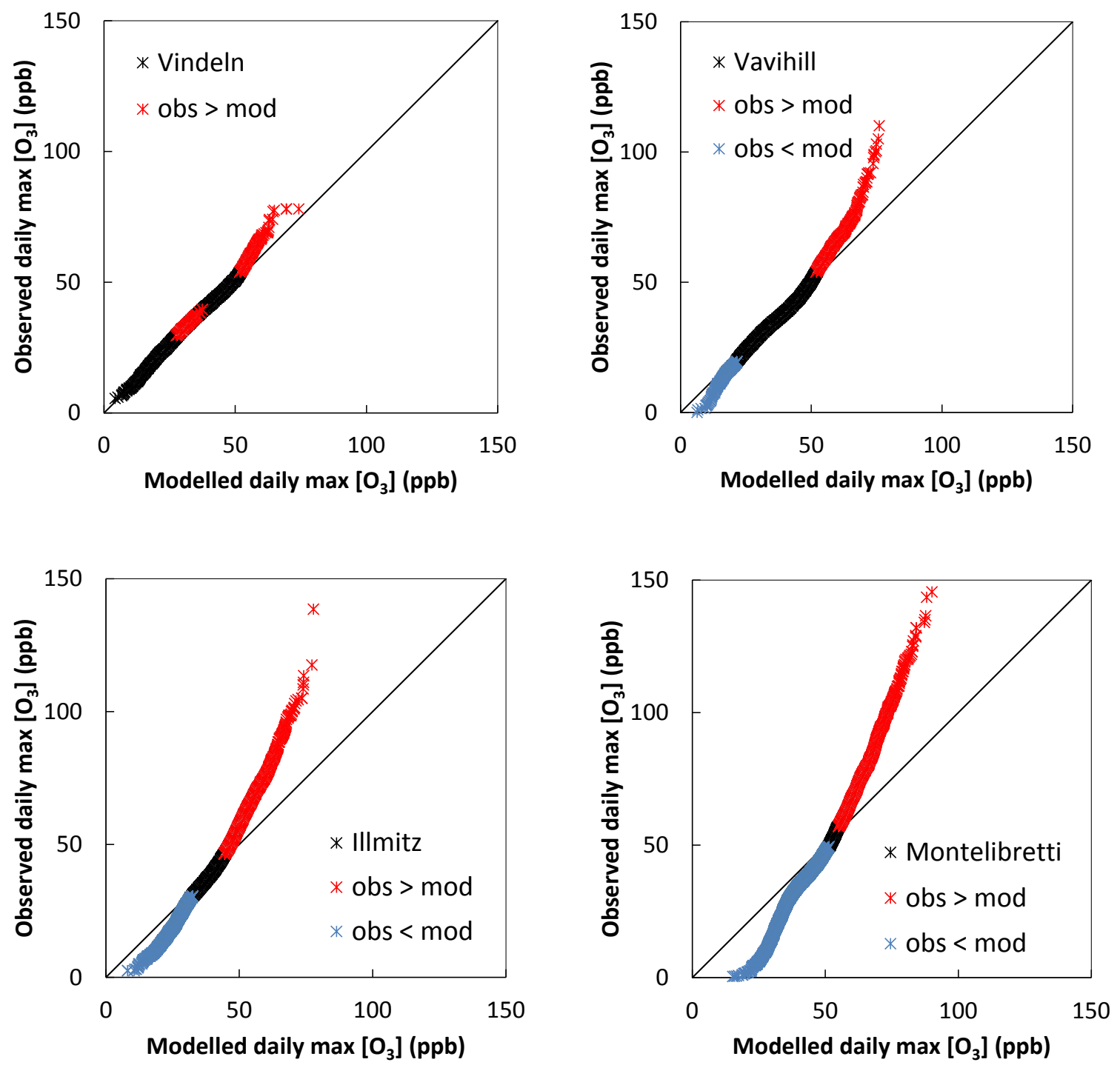

Figure S1. Modelled and observed daily maximum ozone concentration (ppb) at four sites in Europe. Red colour: observations more than 2 ppb higher than model, blue colour: observations more than $2 \mathrm{ppb}$ lower than model. 

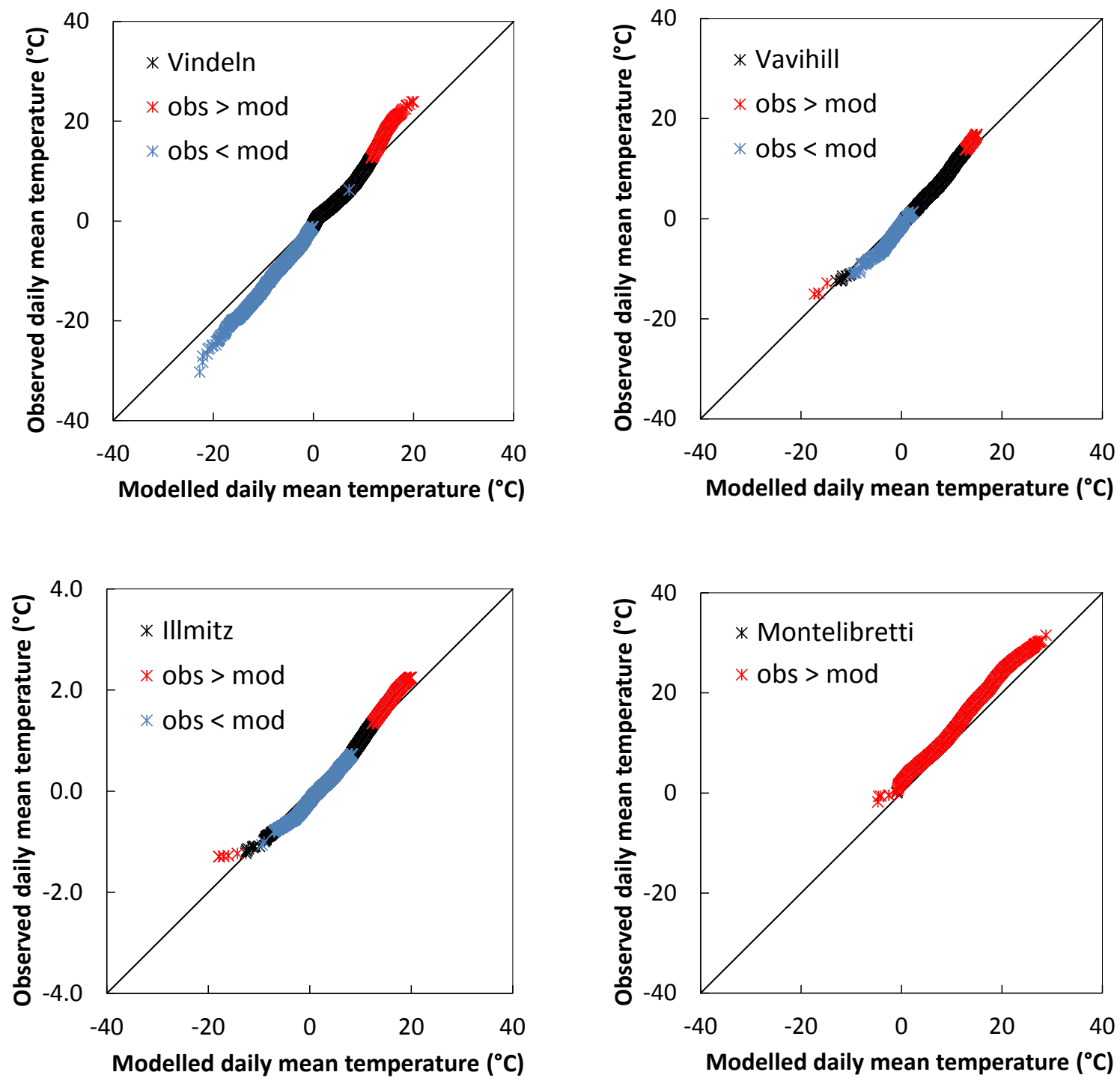

Figure S2. Modelled and observed daily mean temperature $\left({ }^{\circ} \mathrm{C}\right)$ at four sites in Europe. Red colour: observations more than $1^{\circ} \mathrm{C}$ higher than model, blue colour: observations more than $1^{\circ} \mathrm{C}$ lower than model. 

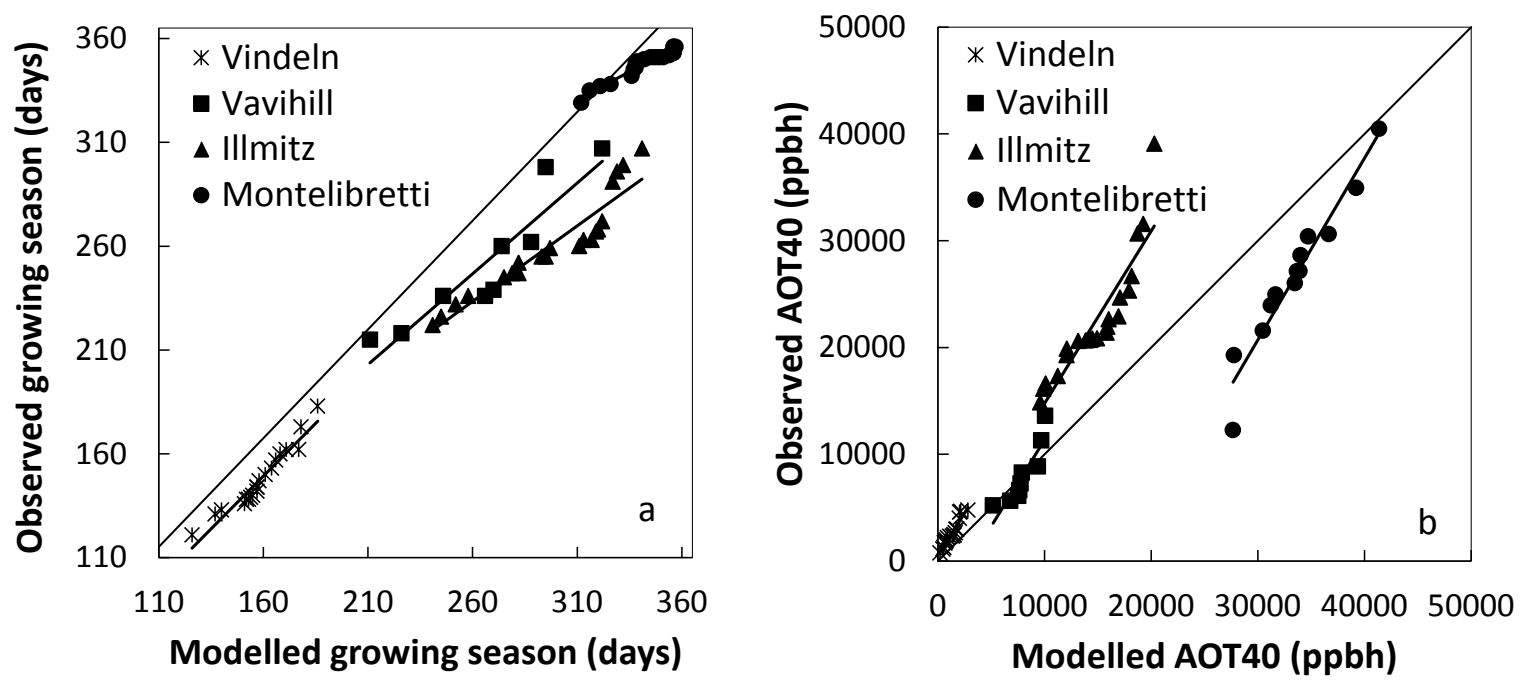

Figure S3. Modelled and observed length of growing season for trees (a) and AOT40 accumulated over the growing season for trees (b) at four sites in Europe. 